\title{
To Each the Same and to Each his Own: A Proposal to Measure Responsibility-Sensitive Income Inequality
}

\author{
By Kurt DeVooght
}

\author{
EHSAL, BRUSSELS
}

Final version received 25 July 2006.

\begin{abstract}
This paper deals with the question of how to incorporate modern responsibility-catering egalitarianism into economic theory on the measurement of income inequality. I present a particular axiomatic expression of the main aspects of such egalitarianism. Then, to measure offensive inequality separately I construct a norm or reference income distribution based upon the axiomatic model to replace the perfectly equal income distribution that used as norm by all common inequality measures. I defend the use of a particular measure of distributional change to determine the degree of offensive inequality, and apply the method to Belgian income data.
\end{abstract}

\section{INTRODUCTION}

Income equality is a modern ideal that appeals to many people, including economists and policy-makers. Apart from some mavericks like Babeuf and Marechal (1794), modern egalitarians (e.g. Rawls 1971, Dworkin 1981a,b, Arneson 1989, Cohen 1989, 1990 and Fleurbaey 1995c,d; 1998) never defend an absolute or perfect income equality where all citizens always have the same income. Theorists usually allow for income differences stemming from differences in needs, effort or preferences. It implies that someone wasting money, for instance, should not be compensated, whereas someone working hard should be allowed to reap the fruits of his effort. This means that many contemporary egalitarians conceive egalitarianism with respect to personal responsibility, thereby generating (different versions of) responsibility-sensitive egalitarianism. Within an economic context, this means, in short, that income inequality for which people cannot be held responsible is offensive, whereas inequality stemming from actions for which they could be held responsible is not offensive and should not appear in the statistics as offensive income inequality. ${ }^{1}$

Unfortunately, traditional income inequality measures (like the Gini coefficient or generalized entropy measures) neglect these allowances for differences in responsibility completely, since they take the perfectly equal income distribution as reference point for measurement. The main aim of this paper, therefore, is to develop a method to measure only the offensive inequality, i.e. inequality for which people cannot be held responsible, based upon an alternative (responsibility-sensitive) norm income distribution. ${ }^{2}$ More specifically, I use the theoretical framework of Bossert and Fleurbaey (1996) to capture the main features of this ethic and to design some adequate reference income distributions. This framework of (re-)distribution seems very suitable for such a task, since it differentiates between characteristics for which people can be held responsible and those for which they should not bear responsibility. This distinction is a prerequisite for my objective to measure only that inequality for which people cannot be held responsible.

The relevance of this exercise stretches even beyond that of adapting economic measurement to contemporary egalitarian thinking. Since policy-makers have only limited resources with which to reduce income inequality, they obviously should give

(C) The London School of Economics and Political Science 2007 
priority to reduce the 'worst' or 'most offensive' inequality. In this respect, a measure that gives account of the 'most offensive' inequality is a helpful analytical tool.

The paper follows the structure of the method. In the first section a model is presented and my interpretation of responsibility-sensitive egalitarianism explained; I then take this further and develop a norm income distribution that deviates from the perfectly equal one taking into account personal responsibility. Section II presents a way to measure the distance between the actual income distribution and the newly designed norm income distribution. Section III contains an empirical application of our method employing Belgian data, and Section IV concludes.

\section{A Responsibility-Sensitive Egalitarian Model}

The responsibility-sensitive egalitarian ethics as it appears in the literature may be summarized as follows. Inequality among individuals is considered as unjust if it is due to factors that are beyond the personal responsibility of the individuals, but it is considered as just if the inequality is due to the exercise of personal responsibility. The entire normative debate about how to discern the factors that are within and beyond the ambit of individual responsibility is beyond the scope of this paper. Therefore the actual allocation of the responsibility cut, i.e. the divide between responsibility and compensation variables, is taken for granted (or already decided upon by the policymaker). I should also add at this stage that from here on I restrict the discussion to income distributions, thus taking income as the relevant equalisandum. Bossert and Fleurbaey (Bossert 1995, Bossert and Fleurbaey 1996) have given concrete content to some responsibility-sensitive ideas in a quasi-linear model of income redistribution. ${ }^{3}$ Although designed for other purposes, I believe that their model, and more specifically the axioms incorporated in it, may provide a basis for the measurement of offensive and inoffensive inequality. First, I describe the model.

I denote the set of real numbers by $\Re$, and $N$ is the set of positive integers. The population in a given society is given by $K=\{1, \ldots, n\}$ where $n \geqslant 2$. There are $r \in N$ individual characteristics that are considered 'responsibility' variables and $c \in N$ 'compensation' variables. Agent $i$ 's $(i \in K)$ vector of responsibility variables is $a_{i}^{R} \in \Re^{r}$, and $i$ 's vector of compensation variables is described by $a_{i}^{C} \in \Re^{c}$. The characteristics vector of $i \in K$ is $a_{i}=\left(a_{i}^{R}, a_{i}^{C}\right) \in \Re^{r+c}$. A characteristics profile is $\bar{a}=\left(a_{1}, \ldots, a_{n}\right) \in \Re^{n(r+c)}$, and can be partitioned into $\bar{a}^{R}=\left(a_{1}^{R}, \ldots, a_{n}^{R}\right) \in \Re^{n r}$ and $\bar{a}^{C}=\left(a_{1}^{C}, \ldots, a_{n}^{C}\right) \in \Re^{n c}$. The set of all characteristics vectors is $\Omega \subseteq \Omega_{R} \times \Omega_{C}$, where $\Omega_{R} \subseteq \Re^{r}, \Omega_{C} \subseteq \Re^{c}$, and $\Omega_{R}, \Omega_{C} \neq \emptyset$. Reference vectors of responsibility and compensation characteristics are denoted by $\tilde{a}^{R} \in \Omega_{R}$ and $\tilde{a}^{C} \in \Omega_{C}$, respectively.

An income function assigns a pretax income to each possible characteristics vector. That is, an income function is a mapping $f: \Omega \rightarrow \Re, a=\left(a^{R}, a^{C}\right) \mapsto f(a)$. Therefore, pretax income is determined by both responsibility and compensation characteristics.

A redistribution mechanism assigns to each pretax income a post-tax income, thereby taking account of the characteristics profile $\bar{a}$ of the population under consideration. Formally, a redistribution mechanism is a mapping $F: \Omega^{n} \rightarrow \Re^{n}, \bar{a} \mapsto F(\bar{a})$, such that

$$
\sum_{i=1}^{n} F_{i}(\bar{a})=\sum_{i=1}^{n} f\left(a_{i}\right) \quad \forall \bar{a} \in \Omega^{n} .
$$

This budget constraint implies that the redistribution does not lead to an efficiency loss, i.e. that we are considering a first-best problem. ${ }^{4}$

(C) The London School of Economics and Political Science 2007 
We restrict ourselves to anonymous redistribution mechanisms, i.e. to mechanisms satisfying

$$
\forall \bar{a} \in \Omega^{n}, \quad \forall i, j \in K, a_{i}=a_{j} \Rightarrow F_{i}(\bar{a})=F_{j}(\bar{a}) .
$$

A responsibility-sensitive egalitarian, however, will point to the possibility that a subset of the characteristics $a_{i}$ is within the responsibility of individual $i$. Her first problem-locating the responsibility cut - then is to partition the vector $a_{i}$ in $\left(a_{i}^{R}, a_{i}^{C}\right)$. The second problem is to establish how this partitioning can be exploited to give a concrete content to the idea of responsibility-sensitivity.

Fleurbaey (1994; 1995a,b,c) and Bossert (1995) have modelled two basic intuitions in this respect. The first intuition reflects the egalitarian aspect of the approach. I call it 'Equal Income for Equal R-variables' (EIER) or 'Full Compensation', and it states that, for all possible $\bar{a} \in \Omega^{n}$, for any two individuals, one should have

$$
a_{i}^{R}=a_{j}^{R} \Rightarrow F_{i}(\bar{a})=F_{j}(\bar{a}) .
$$

If two persons are identical in all characteristics for which they can be held responsible - if they differ only with respect to characteristics for which they must be compensated - then the redistribution mechanism must assign these two persons the same post-tax income.

The second intuition captures the idea of responsibility, i.e. of the limits to be imposed on egalitarianism. I call it 'Equal Transfer for Equal C-variables' (ETEC) or 'Strict Compensation', and it says that, for all possible $\bar{a} \in \Omega^{n}$, for any two individuals, the redistribution mechanism must satisfy

$$
a_{i}^{C}=a_{j}^{C} \Rightarrow F_{i}(\bar{a})-f\left(a_{i}\right)=F_{j}(\bar{a})-f\left(a_{j}\right) .
$$

If two persons have identical compensation characteristics, the differences in their pretax income will reflect only differences in their responsibility characteristics, and hence prima facie there seems no reason why these differences should diminish through the redistribution process. Equation (4) formalizes this by imposing that these two persons should pay the same tax or receive the same transfer. ${ }^{5}$

The main result of Fleurbaey $(1994 ; 1995 a)$ is that the two intuitions of full compensation and strict compensation are in general incompatible as soon as $n \geqslant 4$. Bossert and Fleurbaey (1996), however, characterize several distribution mechanisms that satisfy a combination of one axiom with a weakened version of the other. Since the axiom of strict compensation is far from undisputed (see note 5), I have opted from here on to focus on mechanisms that satisfy full compensation (EIER) but loosen strict compensation. In that case, one may select a distribution scheme within the family of egalitarian-equivalent mechanisms, $F^{E E}$, defined in general as

$$
F_{k}^{E E}(\bar{a})=f\left(a_{k}^{R}, \tilde{a}^{C}\right)-\frac{1}{n} \sum_{i=1}^{n}\left[f\left(a_{i}^{R}, \tilde{a}^{C}\right)-f\left(a_{i}\right)\right] \quad \forall \bar{a} \in \Omega^{n}, \forall k \in K,
$$

where $\tilde{a}^{C}$ is a (freely chosen) benchmark vector. With this mechanism, every agent has a post-tax income equal to the pretax income she would earn if her compensation characteristics were $\tilde{a}^{C}$, plus a uniform transfer.

How can the Fleurbaey-Bossert model contribute to measure both the offensive and the inoffensive parts of inequality in a more appropriate manner? The described family of redistribution mechanisms (5) suggests itself as a family of alternative reference income distributions. It is then only a matter of using a particular alternative reference

(C) The London School of Economics and Political Science 2007 
distribution, instead of the equally distributed one, to get an idea of the degree of offensive inequality. This, however, requires adequate measures, as has been studied in the literature on the reference income approach and the measurement of distributional change. The choice of an appropriate measure is the topic of the next section.

\section{Measuring the Deviation from the Norm}

Basically, the norm or reference income approach incorporates information about differences in non-income characteristics of the income unit in the construction of a reference income distribution $z$. In the present setting, information on personal responsibility is the relevant information to be included. The social planner then determines how much income each individual is entitled to from a responsibility-sensitive point of view, consistent with the given amount of total income available. The answer is the norm or reference income distribution $z$.

In the literature, a lot of attention has been paid to summary methods that capture distributional change, i.e. the distance apart of two distributions, and possess desirable properties. ${ }^{6}$ This research was absolutely necessary because inequality measures could not be used to measure distances between distributions for at least one important reason.

Indeed, in measuring distances between a norm and an observed income distribution, one has to depart from absolute or complete anonymity. ${ }^{7}$ This implies that there might be distributional change without any change in inequality when the norm is complete equality. This can be shown by a simple example. Suppose person A has 5 but ought to have 8 and exactly the opposite applies for person B: he has 8 but should have 5 . For any inequality measure $I(\cdot)$ that takes complete inequality as the norm, it is clear that both distributions - the observed one $f(5,8)$ and the norm distribution $z(8,5)$ - face the same inequality and that $I(f)-I(z)=0$. However, the observed and the norm income of the same income unit should be compared to obtain the distributional change that clearly should deviate from zero. This example shows that a measure of distributional change should not measure inequality with respect to the perfectly equal distribution, nor increments or decrements in such inequality. Cowell emphasizes this essential distinction between the concept of distributional change and the concept of a change in inequality.

In the latter case, anonymity is complete. We can re-label the components of vectors $f$ and $z$ independently and leave $I(f)-I(z)$ unaltered. In the former case anonymity is assured only in a qualified sense: we may reorder the pairs $\left(f_{1}, z_{1}\right),\left(f_{2}, z_{2}\right),\left(f_{3}, z_{3}\right), \ldots$ and leave [the distributional change] unaltered but not permute components of $f$ and $z$ independently. (Cowell 1980, p. 15051 ; adjusted to my own notation).

Consequently, since we are working with a heterogeneous population, the transfer principle that we are used to in conventional inequality measurement is no longer attractive either. A valuable alternative, however, is to require that measured inequality falls because of a transfer of a small amount of income, $\delta$, from a richer income unit $k$ to a poorer one $j$ only if $f_{j} / f_{k}<z_{j} / z_{k}$. This means that the effect of a transfer depends on whether the ratio of the observed incomes of income unit $j$ and $k$ is smaller than the ratios of their reference incomes. It may even lead to situations in which a transfer from a rich to a poor person increases measured inequality if the income unit from which income is transferred has a high $f$ and a high $z$, more specifically if $f_{j} / f_{k}>z_{j} / z_{k} .{ }^{8}$ Intuitively speaking, the closing of the gap between the actual and the norm income of a poor person (as a

(C) The London School of Economics and Political Science 2007 
result of the transfer) does not outweigh the deepening of the already much larger gap between the actual and the norm income of the rich person.

Now, Cowell (1985) has shown that an interesting class of distance measures stands at our disposal, to measure the distance between two income distributions of which the well known family of generalized entropy (GE) inequality measures is a subclass. Cowell's measures of distributional change ensure that the observed income and reference income of the same income unit are compared, that they satisfy the alternative interpretation of the transfer principle discussed above, and that they also possess the desirable properties of symmetry, mean independence, additive decomposability by population subgroups and independence of replications of the population (among others). Measures of distributional change summarize the distance apart of the actual distribution and the norm distribution and could be seen as an indication of the redistribution needed to obtain the norm distribution.

For any two distributions $f$ and $z$ (and both distributions have an equal mean, $\bar{f}=\bar{z}$ ), the class of distance measures can be written in the form (Cowell 1985, Jenkins and O’Higgins 1989)

$$
\begin{aligned}
& J_{\alpha}(f, z)=\frac{1}{n \alpha(\alpha-1)} \sum_{i=1}^{n}\left[\left(\frac{\left(f_{i}\right)^{\alpha}\left(z_{i}\right)^{1-\alpha}}{\bar{f}}\right)-1\right], \quad \alpha \neq 0,1 \\
& J_{1}(f, z)=\frac{1}{n} \sum_{i=1}^{n}\left(\frac{f_{i}}{\bar{f}}\right) \log \left(\frac{f_{i}}{z_{i}}\right) \\
& J_{0}(f, z)=\frac{1}{n} \sum_{i=1}^{n}\left(\frac{z_{i}}{\bar{z}}\right) \log \left(\frac{z_{i}}{f_{i}}\right)
\end{aligned}
$$

In this context, distribution $f$ is the observed income distribution and $z$ is the norm income distribution. Parameter $\alpha$ summarizes the sensitivity to changes in the distribution in different parts of the distribution: for a large and positive $\alpha$, the index is particularly sensitive to changes that affect the upper tail, whereas for $\alpha$ negative, the index is sensitive to changes that affect the lower tail. ${ }^{9}$

It is my intention to apply this general class of distance measures to quantify the distance between the observed income distribution and the responsibility-sensitive reference or comparative distribution. Bossert and Fleurbaey specify redistributive mechanisms (5) of which the outcome may serve as fully specified norm income distributions.

Now the tools are ready to be used in the empirical application. From the data I will now construct the fully specified reference incomes from the class $F^{E E}$. I will then calculate the offensive distance between the observed income distribution and the norm income distribution using equation (6) for different values of $\alpha$.

\section{EMPIRICAL APPLICATION}

\section{The data}

All data are taken from the seventh wave of the Panel Study on Belgian Households (PSBH). The data were gathered during spring 1998, which implies that the income data refer to income earned during 1997. The PSBH98 data-set contains information on 7021 adults aged 16 or over. Of these adults, 3618 had a regular job-defined as a job that

(C) The London School of Economics and Political Science 2007 
demands more than 15 working hours a week. Individuals who work less are not taken into account in order to avoid the results being biased by data of students working parttime. Moreover, self-employed people (525) are left out, which reduces the data-set to 3093 relevant observations. Self-employed people are not useful to this exercise since we want to estimate a labour income equation, and earnings from labour cannot be separated from earnings from investment in the case of the self-employed. As a result of missing variables another 1247 observations had to be dropped, resulting in a data-set containing 1846 individuals for whom all needed information was available.

The jobless (and all those working fewer than 15 hours a week), the self-employed and the pensioners are thus not taken into account. Obviously, these groups are not drawn randomly from the population. This calls for a correction so that the results of the estimation do not suffer from sample selection bias. The problem can be solved by using Heckman's two-step estimation (see Heckman 1979).

Yearly pretax income (in Belgian francs) was computed as the monthly wage times the number of months the respondent had received that amount. Since pretax data on extra premiums (such as sales premiums), allowances (13th and 14th month, holiday money, etc.) and other transfers are lacking, such data are not included in the income variable.

First, in order to calculate the reference incomes, we need to know how (much) each personal characteristic contributes to the total income. Those variables are then labelled either 'responsibility variable' or 'compensation variable' and are used to calculate $F^{E E}$. However, the contribution of each personal characteristic to total income is not readily available and should be estimated.

\section{The estimation}

Since we do not have knowledge of the income function, one could estimate income as a function of the personal characteristics using regression analysis. As sample selection biases are not implausible, I performed Heckman's two-step estimation procedure. In the first stage of the procedure I estimated whether or not someone holds a job. This is a binary variable and hence probit is an appropriate model. My selection equation is therefore $^{10}$

$$
\begin{aligned}
\operatorname{Pr}(j o b=1)= & \alpha+\beta_{1} \text { gender }+\beta_{2} \text { ver }+\beta_{3} \text { age }+\beta_{4} \text { marry }+\beta_{5} \text { child } \\
& +\beta_{6} \text { nation }+\beta_{7} \text { region } 1+\beta_{8} \text { region } 2+\beta_{9} \text { edu } 1+\beta_{10} \text { edu } 2 \\
& +\beta_{11} \text { edu } 3+\beta_{12} \text { edu } 4+\beta_{13} \text { edu } 5+\varepsilon .
\end{aligned}
$$

I then used the coefficients of the regression of the selection equation to calculate Heckman's lambda, which will be included in the regression of the labour income equation as an independent variable.

A non-additively separable specification of the labour income function is likely to be appropriate in representing real-world situations since the influences of responsibility variables and compensation variables are often entangled. In the present model it can be interpreted as the situation in which income arising from responsible factors is dependent upon the level of compensation characteristics, or vice versa. An attractive non-additively separable specification of the income function is the semi-logarithmic functional form. Since my theory does not suggest anything specific, I took the natural logarithm of pretax labour incomes as the left-hand side variable. This means that I assume multiplicative

(C) The London School of Economics and Political Science 2007 
effects as I propose to work with the following equation:

$$
\begin{aligned}
f(a)= & e^{\left(\beta_{0}\right)} \cdot e^{\left(\beta_{1} \text { houry }\right)} \cdot e^{\left(\beta_{2} \text { gender }\right)} \cdot e^{\left(\beta_{3} \text { age }\right)} \cdot e^{\left(\beta_{4} \text { age } 2\right)} \cdot e^{\left(\beta_{5} \text { marry }\right)} \cdot e^{\left(\beta_{6} \text { nation }\right)} \\
& \cdot e^{\left(\beta_{7} e d u 1\right)} \cdot e^{\left(\beta_{8} e d u 2\right)} \cdot e^{\left(\beta_{9} e d u 3\right)} \cdot e^{\left(\beta_{10} e d u 4\right)} \cdot e^{\left(\beta_{11} e d u 5\right)} \cdot e^{(\delta \text { hecklam })}
\end{aligned}
$$

This could be log-transformed to be estimated linearly by OLS, which gives ${ }^{11}$

$$
\begin{aligned}
\log (f(a))= & \hat{\beta}_{0}+\hat{\beta}_{1} \text { houry }+\hat{\beta}_{2} \text { gender }+\hat{\beta}_{3} \text { age }+\hat{\beta}_{4} \text { age } 2 \\
& +\hat{\beta}_{5} \text { marry }+\hat{\beta}_{6} \text { nation }+\hat{\beta}_{7} \text { edu } 1+\hat{\beta}_{8} \text { edu } 2+\hat{\beta}_{9} \text { edu } 3 \\
& +\hat{\beta}_{10} \text { edu } 4+\hat{\beta}_{11} \text { edu } 5+\hat{\delta} \text { hecklam }+\hat{\varepsilon} .
\end{aligned}
$$

I incorporated age as a proxy for experience, and age-squared (age2) because empirical studies show that wage - the main part of labour income - is a decreasing positive function of age. To capture the effect of education, five dummy variables are included. Not included is the lowest level of education, i.e. primary schooling or less, which serves as a benchmark. The choice of the control variables capturing personal characteristics is set by the available data and by checks on whether their contribution is significant. Regional and sectorial (private/public) differences seem to be insignificant and thus are not included.

Let us consider the estimation results (Table 1). ${ }^{12}$ All parameters are significant at a $10 \%$ level except the Heckman lambda. This might indicate that not being at work is not linked with unobservable personal characteristics or individual preferences. The sign of

TABLE 1

Regression Results: Non-additively Separable Income Function

\begin{tabular}{lcrrrrr}
\hline Source & & SS & & d.f. & \multicolumn{1}{c}{ MS } \\
\hline Model & & 318.888567 & & 12 & & 26.5740473 \\
Residual & & 361.476027 & & 1833 & & 0.197204597 \\
Total & & 680.364594 & & 1845 & & 0.368761297 \\
\hline logbruty & Coef. & Std error & \multicolumn{1}{c}{$t$} & $P>|t|$ & {$[95 \%$ conf. interval] } \\
\hline hecklam & 0.1810966 & 0.1402045 & 1.292 & 0.197 & -0.0938806 & 0.4560739 \\
houry & 0.000384 & 0.000027 & 11.237 & 0.000 & 0.0003311 & 0.0004369 \\
gender & -0.2976156 & 0.0463995 & -6.414 & 0.000 & -0.3886171 & -0.2066141 \\
age & 0.1079085 & 0.0085524 & 12.617 & 0.000 & 0.0911349 & 0.1246821 \\
age2 & -0.0010621 & 0.0001079 & -9.842 & 0.000 & -0.0012737 & -0.0008504 \\
marry & 0.120512 & 0.0536103 & 2.248 & 0.025 & 0.0153583 & 0.2256556 \\
nation & -0.2156308 & 0.062476 & -3.451 & 0.001 & -0.3381625 & -0.093099 \\
edu1 & 0.1916196 & 0.0683262 & 2.804 & 0.005 & 0.0576143 & 0.325625 \\
edu2 & 0.3958726 & 0.0825079 & 4.798 & 0.000 & 0.2340533 & 0.557692 \\
edu3 & 0.6648619 & 0.1235601 & 5.381 & 0.000 & 0.4225285 & 0.9071952 \\
edu4 & 0.6839793 & 0.1206401 & 5.670 & 0.000 & 0.4473729 & 0.9205857 \\
edu5 & 0.8151532 & 0.1146303 & 7.111 & 0.000 & 0.5903335 & 1.039973 \\
cons & 9.781276 & 0.2502153 & 33.091 & 0.000 & 9.290539 & 10.27201 \\
\hline
\end{tabular}

Notes

Number of obs. $=1846 ; \quad F(12,1833)=134.75 ;$ Prob $>F=0.0000 ; R$-squared $=0.4687 ;$ Adj $R$-squared $=0.4652 ;$ Root MSE $=0.44408$.

(C) The London School of Economics and Political Science 2007 
gender is as expected: being a woman is on average not favourable for one's labour income. That the non-Belgians earn less might be due to 'poor' immigrants (even outweighing the 'rich' Brussels' Eurocrats). Married people on average earn more, and the additional income resulting from schooling increases with the level of education.

\section{The construction of the norm income distribution}

We can now take the next step. Since I have estimated how much each personal characteristic contributes to total labour income, we can construct a norm income distribution belonging to the class of egalitarian equivalent redistributions $F^{E E}$, which has been defined as

$$
F_{k}^{E E}(\bar{a})=f\left(a_{k}^{R}, \tilde{a}^{C}\right)-\frac{1}{n} \sum_{i=1}^{n}\left[f\left(a_{i}^{R}, \tilde{a}^{C}\right)-f\left(a_{i}\right)\right] .
$$

However, the construction of the norm income is far from straightforward. In the first place, we can no longer escape choices about which variables are to be considered responsibility variables and which compensation ones. For each element of estimation (9), one has to determine the class of variables it belongs to. We deal with this responsibility cut first. Second, introducing a benchmark or reference vector $\tilde{a}^{C}$ to calculate hypothetical incomes from which norm incomes could be derived introduces the need to determine sound and reasonable benchmark values for each term considered as a compensation variable.

The responsibility cut We can no longer escape choices about which variables are to be considered responsibility variables and which compensation ones. Focusing first on the assignment of the two technical components of estimation - the regression constant and the error term - the easiest assignment is that of the 'equally distributed' regression constant. It does not matter for the outcome of any $F^{E E}$ whether you put it in $a^{R}$ or $\tilde{a}^{C}$. This follows straightforwardly from the definition of $F^{E E}$.

The most difficult problem is the treatment of the error term. The Bossert-Fleurbaey framework is based on the assumption that identical persons have the same pretax income. This implies that every part of every income exhaustively should be assigned as caused by either a responsibility or a compensation variable. If otherwise identical persons de facto have a different pretax income, this difference should be assigned to either $a^{R}$ or $a^{C}$, even if this means that having to introduce new variables. The error term effectively acts as a collector of unassignable income differences. It guarantees that persons who are identical in terms of included control variables are 'able' to earn different pretax incomes.

The error or disturbance term should be suitably dealt with. One might have good normative reasons to suppose that this term summarizes effects for which one should be held responsible and to consider it as a responsibility variable. Alternatively, one might prefer to consider the disturbance term as a combination of unobserved effects for which one should be compensated. Then one certainly does not disadvantage anyone by wrongly assigning inequality to characteristics for which one is responsible. Indeed, many will be opposed to being held responsible for unknowns. But again, this is mainly a normative question and alternative arguments may emerge. ${ }^{13}$ For the remainder of this section, I have taken the fundamental option to treat the error term as a compensation variable. $^{14}$

(C) The London School of Economics and Political Science 2007 
The responsibility cut of the other variables cannot be taken for granted either. I strongly feel that this cut has to be made by societal consensus, or at least by people's representatives in democratic institutions. Subject to the particular normative choices a society might make, various scenarios are conceivable. One might think of the status quo with regard to the egalitarian ethic: one assigns all variables to the compensation part, implying that the equal distribution is the norm income distribution - each should have mean income. It could be shown (see note 9) that the measures of distributional change (6) in that case collapse into the class of generalized entropy inequality measures. For further reference, I refer to this particular responsibility cut as reference GE.

It is equally straightforward to deal with a society that agrees upon some kind of 'maximal responsibility', where all variables (including the error term) are considered as responsibility variables, implying that no redistribution whatsoever is required.

Alternatively, we might think of a society that reaches a consensus that the number of hours worked is one - although the only one - variable for which people should be held responsible. Such agreement on 'minimal responsibility' might reflect a paternalistic society, or one with a strong inclination to social intervention that takes a first step towards the responsibilization of inequality. This responsibility cut is called reference A.

One could also consider societies in which consensus upon some sort of 'intermediate responsibility' prevails, i.e. where some but not all variables are assigned to the responsibility part. One might for instance add the estimated income resulting from being married and one's level of education to the responsibility part (thereby neglecting the ethical (im-)plausibility of this shift).

Since I consider the responsibility cut as a decision to be made by society, I calculate the offensive inequality with respect to different allocations of the responsibility cut. In additon to responsibility cuts reference GE and reference A, I also calculate offensive inequality with respect to reference $\mathrm{B}$ (which takes hours worked and marriage as responsibility ( $\mathrm{R}$-)variables), reference $\mathrm{C}$ (hours worked, marriage and education are $\mathrm{R}$ variables), reference D (hours worked, marriage, education and the Heckman lambda), reference $\mathrm{E}$ (hours worked, marriage and the Heckman lambda) and reference $\mathrm{F}$ (which takes only the Heckman lambda as R-variable). Finally, reference $\mathrm{G}$-like reference A - considers only the number of hours worked as a responsibility variable but applies a different benchmark vector. The choice of the benchmark levels for the compensation variables is the topic of the next section.

The benchmark The cut between responsibility and compensation variables has to be supplemented by a choice of a fixed benchmark level of the compensation variables. We next consider the choices that are necessary to calculate $f\left(a_{k}^{R}, \tilde{a}^{C}\right) \forall k$. Since I decided to consider the error term as a compensation variable, I think it is not unreasonable to include the error term in the benchmark vector with the value of the log of the mean of $e^{\hat{\varepsilon}}\left(\log \left(\overline{e^{\hat{\varepsilon}}}\right)=0.0836\right)$. I further added benchmark levels for the $\mathrm{C}$-variables for the various allocations of the responsibility cut (GE to G) as summarized in Table 2. The columns give the values used to calculate the hypothetical income $f\left(a_{k}^{R}, \tilde{a}^{C}\right)$. A number in the table means that that particular variable is fixed at that level and thus belongs to the benchmark compensation vector. The name of the variable in the table means that the variable as such is included in the calculation of $f\left(a_{k}^{R}, \tilde{a}^{C}\right)$ as a responsibility variable.

Could our responsibility-sensitive theory give information on how the levels of the variables included in $\tilde{a}^{C}$ could be fixed? One might suggest that one plausible view is to grant people responsibility for the part of the income that is independent of the compensation factors, but not for the part that depends upon compensation factors. This

(C) The London School of Economics and Political Science 2007 
TABLE 2

Normative ChOICES FOR $F^{E E}$-NORM

\begin{tabular}{lcccccccc}
\hline$f\left(a_{k}^{R}, \tilde{a}^{C}\right)$ & $\mathrm{GE}$ & $\mathrm{A}$ & $\mathrm{B}$ & $\mathrm{C}$ & $\mathrm{D}$ & $\mathrm{E}$ & $\mathrm{F}$ & $\mathrm{G}$ \\
\hline houry & 1900.7 & houry & houry & houry & houry & houry & 1900.7 & houry \\
gender & 1 & 1 & 1 & 1 & 1 & 1 & 1 & 0 \\
age & 16 & 16 & 16 & 16 & 16 & 16 & 16 & 60 \\
marry & 0 & 0 & marry & marry & marry & marry & 0 & 1 \\
nation & 1 & 1 & 1 & 1 & 1 & 1 & 1 & 0 \\
edu1 & 0 & 0 & 0 & edu1 & edu1 & 0 & 0 & 0 \\
edu2 & 0 & 0 & 0 & edu2 & edu2 & 0 & 0 & 0 \\
edu3 & 0 & 0 & 0 & edu3 & edu3 & 0 & 0 & 0 \\
edu4 & 0 & 0 & 0 & edu4 & edu4 & 0 & 0 & 0 \\
edu5 & 0 & 0 & 0 & edu5 & edu5 & 0 & 0 & 1 \\
heckl & 0 & 0 & 0 & 0 & heckl & heckl & heckl & 1 \\
\hline
\end{tabular}

is the spirit of the responsibility-sensitive egalitarian ethics; but now one has to internalize this famous cut into the effects of responsibility variables themselves. One could do the following: anyone who works one hour extra $\left(\in a^{R}\right)$ is entitled to keep the fruits of his additional effort as far as his extra income is independent of his compensation variables $\left(a^{C}\right)$. The part of the income that is independent of the compensation variables is taken to be the income one could earn if one were the most disadvantaged in terms of earning power or the least marginally productive member of the economy. If you earn more than the least advantaged for the same level of the responsibility variables, this is due to personal characteristics of which you are the lucky possessor, and for that very reason is open for redistribution. This is what Tungodden (2005) proposes in the context of first-best taxation.

A word of caution is needed. I am not fully convinced that this is an appealing argument for choosing the least favourable circumstances as a reference for the computation of the $F^{E E}$-norm. Basically, the idea that some part of the income does not depend on compensation variables such as talent is probably nonsensical. Even the income of the least advantaged person is determined by his compensation variables. Nevertheless, I think that applying the least favourable circumstances as benchmark is appealing for another reason. Among the egalitarian equivalent mechanisms, this reference leads to the most egalitarian outcome distribution. If a society is cautious about accepting inequalities on the basis of responsibility (say, because one is not sure that agents are really responsible for their labour), then taking the most egalitarian option makes sense. I therefore take the prudent stance that only a minimal portion is attributed to the responsibility part. ${ }^{15}$

In our Belgian sample, the least advantaged reference person is taken to be an unmarried (marry $=0)$, non-Belgian (nation $=1)$, 16-year-old $($ age $=16)$ uneducated $(e d u=0)$ woman $($ gender $=1)$ with no psychological characteristics captured by Heckman's lambda $(\lambda=0)$. For instance, reference GE calculates $f\left(a_{k}^{R}, \tilde{a}^{C}\right)$ using the estimated coefficients for such a person working the average number of hours (1900.7 a year). All variables are considered compensation variables and are fixed at a particular level in a non-arbitrary way. Reference A then keeps the compensation variables fixed at the same level, but considers hours worked as the only responsibility variable. I gradually moved variables from $\tilde{a}^{C}$ to $a^{R}$ (references $\mathrm{B}, \mathrm{C}$ and $\mathrm{D}$, respectively). Reference $\mathrm{E}$

(C) The London School of Economics and Political Science 2007 
TABLE 3

Distributional Change with $F^{E E}$-NORM ${ }^{\mathrm{a}}$

\begin{tabular}{lccc}
\hline$F^{E E}$ & $J_{0}$ & $J_{1}$ & $J_{2}$ \\
\hline Reference GE & 0.15420 & 0.13836 & 0.16923 \\
Reference A & 0.15030 & 0.13485 & 0.16547 \\
Reference B & 0.14919 & 0.13394 & 0.16432 \\
Reference C & 0.13919 & 0.12370 & 0.15072 \\
Reference D & 0.13806 & 0.12257 & 0.14929 \\
Reference E & 0.14936 & 0.13416 & 0.16473 \\
Reference F & 0.15526 & 0.13932 & 0.17042 \\
Reference G & 0.13189 & 0.11867 & 0.15947 \\
\hline
\end{tabular}

${ }^{\mathrm{a}}$ Error term is included in $\tilde{a}^{C}$.

introduces hecklam at another stage in the sequence (after B), and reference $\mathrm{F}$ takes hecklam as the only responsibility variable. For illustrative reasons, the benchmark level of the most advantaged person has been calculated as reference $\mathrm{G}$.

The results The results of measuring the distributional change between the actual and the calculated norm income distribution for different values of $\alpha(\alpha=0,1,2)$ are given in Table 3. ${ }^{16}$ The first line gives the results of the generalized entropy measures, since the measures of distributional change collapse into the class of generalized entropy measures when all variables are compensation variables. All inequality is judged offensive, as is common practice in traditional inequality measurement. Reference A considers the case where the number of hours worked is the only responsibility variable. The result of this case is given on the second line, and in comparison with the first line should be read as follows: the distance between the actual distribution and the norm distribution $F^{E E}$ (built upon one responsibility variable, namely number of hours worked) is smaller than the distance between the actual distribution and the distribution where everyone gets mean income. The distance has decreased by about $2.5 \%$ (measured by $J_{0}$ ).

Sequentially adding more variables to the responsibility part, keeping benchmarks constant, decreases distances (e.g. a $10 \%$ decrease in going from reference GE to reference D). This result, however, depends partly on the order in which the variables are sequentially added, as becomes evident from reference E.

This main result points to the fact that responsibility-sensitive inequality measurement considers about $90 \%-97.5 \%$ of traditionally measured income inequality as offensive-depending on the normative choices concerning the responsibility cut and the benchmark vector. The decrease of the distances might seem quite small. The choice of the benchmark vector $\tilde{a}^{C}$ is the determining element here. Recall equation (10). I have chosen a 'conservative' benchmark vector such that it represents the least advantaged member of the society under scrutiny. That means that $f\left(a_{k}^{R}, \tilde{a}^{C}\right) \forall k$ will generate quite low reference incomes. The second term of (10) implies that much of the actual income will disappear in a basket which will be divided equally among all. Thus, the chosen benchmark has a huge redistributive effect, which means that the norm income distribution is approaching the case where all should receive equal (average) income (the GE case). Note that adopting the benchmark vector $\tilde{a}^{C}$ of the most advantaged individual (reference $\mathrm{G}$ ) leads to the smallest $J_{0}$ of all. Recall that reference $\mathrm{G}$ differs

(C) The London School of Economics and Political Science 2007 
from reference A only in the benchmark vector (most advantaged versus least advantaged), but the results turn out to be highly divergent: a $2.5 \%$ decrease from reference GE to reference A but a $15 \%$ decrease from reference GE to reference G.

Finally, taking the Heckman lambda as a responsibility variable, which is ethically rather unattractive since it collects unknowns, hints at a remarkable aspect of this procedure. Adding a variable to the responsibility part does not necessarily mean that the distance to the norm reduces, as is the case in the penultimate row. ${ }^{17}$ Taking Heckman's lambda as the only responsibility variable (reference F) even indicates that the situation without responsibility variables (reference GE) is not the upper bound of distributional change. Intuitively speaking, this occurs when the distribution of the variable in question is negatively correlated with the actual income distribution. There is thus no monotone (decreasing) relationship between the number of variables included in vector of compensation variables and the distance between the actual and the norm distribution.

\section{CONCLUSION}

The norm income approach to income inequality measurement proves to be a particularly valuable tool in the hands of the responsibility-sensitive egalitarian. His ethics concentrate on the individualized normative incomes that each citizen in the best of circumstances should have. However, reality often diverges from the constructed ideal world of the kind-hearted theorist. Summary methods may capture such ethically 'offensive' divergences in a single index, and subsequently distributions may be ordered according to the degree of ethical 'offensiveness'. The set of attractive properties, including a qualified reading of anonymity and the transfer principle and the presence of a sensitivity parameter, prompted me to use the measures of distributional change as described by Cowell (1985).

The crucial part, however, is the construction of the responsibility-sensitive norm income for each individual of the society under scrutiny. I opted to interpret a readily available and attractive redistributive scheme $-F^{E E}$ - introduced in the literature by Bossert and Fleurbaey. I first decomposed the total income of each person into income resulting from responsibility variables and income arising from compensation variables. I performed a regression analysis in order to do so. A decision had to be made about the responsibility cut, the assignment of the 'equally distributed' regression constant and the person-specific disturbance term. I next calculated the reference income $F^{E E}$ (for different benchmarks). Finally, I calculated the distributional change $J_{\alpha}$ between the observed income distribution and the reference income distribution for different values of $\alpha$. The results can be seen as an indication of how far incomes actually are from the norm distribution.

Interesting results have been derived from Belgian pretax labour income data. For a number of reasonable responsibility cuts and a 'conservative' benchmark vector, I derived that the distance between the actual distribution and the $F^{E E}$ norm distribution is about $90 \%-97.5 \%$ of the distance between the actual distribution and the equal distribution. However, one should not attach too much importance to this specific percentage range, since another distance measure might give a totally different one.

This brings us to some of the shortcomings of my approach. First, a sensitivity analysis that examines the impact on the results of the use of different distance measures was from the outset postponed to future research. I am also well aware that the analysis

(C) The London School of Economics and Political Science 2007 
focuses more on summary indices than on the ordering of distributions in general. This too might be a topic for future discussion.

Second, the main inconvenience of the norm income approach is that, in the case of a non-additively separable income function, the 'ideal' or the 'norm' distribution cannot be defined (unequivocally). In that case benchmark values have to be fixed, and I have made an attempt to do so in a non ad hoc way. I agree that more work could be done on this. Many other choices also have to be made. On some technical issues about where to assign the effects of some variables $(\alpha, \lambda, e)$ an economist could make valuable suggestions, whereas on the responsibility cut within vector $a$ societal consensus should be sought. In general, such flexibility is not a bad thing. The approach is able to incorporate the many convictions that policy-makers or politicians might have and would like to see implemented.

Other specifications of non-additively separable income functions should be applied. In particular, functions incorporating multiplicative effects seem to be promising. For instance, one's hourly wage (given houry is an R-variable) is higher the more educated one is (given education is a C-variable). Consequently, hard-working but less educated people earn less than equally hard-working but better educated ones, all other things equal. Although both make the same level of effort, or more generally the same vector $a^{R}$, the income following their efforts is different owing to differences in $a^{C}$.

Finally, one may wonder how the responsibility-sensitive egalitarian approach deals with differences in needs. For example, one might lead a relatively normal life (and earn a normal income), but only at the cost of expensive treatment or drugs. If society wants to compensate for these and similar medical costs and account for it in inequality measurement, the reference incomes should be suitably adjusted.

\section{APPENDIX A: LIST OF CONTROL VARIABLES}

- Houry: This variable gives the total amount of hours worked per year. It has been computed as the average number of hours actually worked per week (not the number of hours stated in the contract, and ranging from 15 to 90 hours per week) times 49 weeks.

- Age: The age of the respondent.

- Age2: The square of age to capture the concavity of the age earnings (and thus allowing for a certain degree of nonlinearity).

- Edu0: Dummy taking the value 1 if highest education of the respondent is primary schooling or less.

- Edul: Dummy taking the value 1 if highest education of the respondent is lower secondary schooling.

- Edu2: Dummy taking the value 1 if highest education of the respondent is higher secondary schooling.

- Edu3: Dummy taking the value 1 if highest education of the respondent is higher education outside university (short type $=$ less than three years).

- Edu4: Dummy taking the value 1 if highest education of the respondent is higher education outside university (long type $=$ more than three years).

- Edu5: Dummy taking the value 1 if the respondent holds a university degree.

- Gender: Dummy taking the value 1 for women.

- Nation: Dummy taking the value 0 for respondents with the Belgian nationality.

- Region1: Dummy taking the value 1 for Brussels.

- Region2: Dummy taking the value 1 for the Walloon provinces.

- Region3: Dummy taking the value 1 for the Flemish provinces.

- Sector: Dummy taking the value 1 if the respondent is working in the public sector.

- Ver: Dummy taking the value 1 for those being member of a socio-cultural society or club.

(C) The London School of Economics and Political Science 2007 
- Child: number of children for which one receives child allowances (children from birth until the moment that they are self-supporting, up to the age of 25).

- Marry: Dummy taking the value 1 if married.

- Hecklam: Heckman's lambda - see text.

\section{APPENDIX B: RESULTS OF ESTIMATION OF PROBIT MODEL}

Table A1 presents the results of the probit model estimation.

TABLE A1

Probit Estimation Results

\begin{tabular}{lccrccc}
\hline 0000EL & Coef. & Std error & \multicolumn{1}{c}{$z$} & $P>|z|$ & \multicolumn{1}{c}{$[95 \%$ conf. interval] } \\
\hline gender & -0.4737988 & 0.0389227 & -012.173 & 0.000 & -0.5500859 & -0.3975118 \\
ver & -0.0104355 & 0.0381374 & -0.274 & 0.784 & -0.0851834 & 0.0643124 \\
age & -0.0234361 & 0.0013929 & -16.825 & 0.000 & -0.0261661 & -0.020706 \\
marry & 0.4842969 & 0.0426124 & 11.365 & 0.000 & 0.4007781 & 0.5678157 \\
child & 0.0954256 & 0.0211989 & 4.501 & 0.000 & 0.0538766 & 0.1369747 \\
nation & -0.3152162 & 0.0886634 & -3.555 & 0.000 & -0.4889933 & -0.141439 \\
region1 & 0.145092 & 0.0661661 & 2.193 & 0.028 & 0.0154088 & 0.2747751 \\
region2 & 0.1138813 & 0.0404967 & 2.812 & 0.005 & 0.0345093 & 0.1932533 \\
edu1 & 0.3452872 & 0.0760274 & 4.542 & 0.000 & 0.1962762 & 0.4942981 \\
edu2 & 0.5713543 & 0.0742427 & 7.696 & 0.000 & 0.4258413 & 0.7168673 \\
edu3 & 1.083145 & 0.0801231 & 13.519 & 0.000 & 0.9261069 & 1.240184 \\
edu4 & 1.008828 & 0.0960759 & 10.500 & 0.000 & 0.820523 & 1.197134 \\
edu5 & 0.9471183 & 0.0868566 & 10.904 & 0.000 & 0.7768826 & 1.117354 \\
cons & -0.2707348 & 0.0971327 & -2.787 & 0.005 & -0.4611115 & -0.0803582 \\
& & & & & &
\end{tabular}

Notes

Log likelihood $=-3177.5268$

Number of obs. $=6166 ;$ chi $^{2}(13)=1171.67$; Prob $>$ chi $^{2}=0.0000 ;$ Pseudo $R^{2}=0.1557$.

\section{NOTES}

1. An early attempt to include the intuition that some income inequalities are 'spurious', not 'offensive', not 'inequitable' or even 'economically functional', can be found in the proposals of Morton Paglin $(1975,1977,1979,1989)$. For critical comments, see Danzinger et al. (1977), Johnson (1977), Kurien (1977), Minarik (1977), Nelson (1977), Wertz (1979), Formby and Seaks (1980), Formby et al. (1989).

2. This paper is not the first attempt to do so. Peragine (2004) has established dominance criteria for unambiguous social ranking of income distributions on the basis of the 'opportunity egalitarian ethics' which basically comes to the same as the 'responsibility-sensitive egalitarian ethics'. The present approach however focuses more specifically on the construction of an ethically underpinned norm income distribution and the development of a cardinal measure.

3. It is clear that this interprets the Bossert-Fleurbaey framework as a model of how to redistribute, given that people have made choices according to their pretax wage rate. Facing a different pretax wage rate would have led some to perform a different amount of relevant effort. As in traditional inequality measurement, I take the actual choices of people for granted. This implies for instance that someone who prefers to work less because his pretax wage rate has decreased has to bear the consequences of his choice. Some however might find that responsibility-sensitive egalitarianism does not require the person to bear the consequences. Incorporating that idea however is left for further research.

4. This might seem an inappropriate framework for real-world analysis of income distributions. In what follows this kind of redistribution will be used only to develop a norm income distribution and not to represent real-world distributions. A norm income distribution represents how things should look in an ideal world, and efficiency losses are no part of that world.

5. Notice that ETEC is one among many interpretations of the principle of responsibility (see Bossert and Fleurbaey 1996, Cappelen and Tungodden 2003, Tungodden 2005). These authors however develop

(C) The London School of Economics and Political Science 2007 
various reasons why, in particular cases, differences in pretax income should diminish through the redistribution process.

6. On measuring distances between income distributions, see Cowell (1980, 1985), Ebert (1984), Jenkins (1994), Jenkins and O'Higgins (1989), Shorrocks (1982) and Silber (1995).

7. Absolute anonymity means that reordering the incomes of the observed income distribution and/or reordering the incomes of the norm income distribution does not change the measured distance between both distributions.

8. Other specific cases lead to specific conditions. Always considering a transfer from a richer income unit $k$ to a poorer one $j$, which does not change the norm income distribution in any way, inequality decreases; for $z_{j}=z_{k}$ if $f_{j}<f_{k}$; for $f_{k}=z_{k}$ if $f_{j}<z_{j}$; for $f_{j}=z_{j}$ if $f_{k}>z_{k}$; for $f_{k}>z_{k}$ if $f_{j} \leqslant z_{j}$; if both $f_{k}>z_{k}$ and $f_{j}>z_{j}$ if $\left(f_{j}-z_{j}\right) / z_{j}<\left(f_{k}-z_{k}\right) / z_{k}$. This can be checked easily from the general condition $f_{j} / f_{k}>z_{j} / z_{k}$ rewritten as proportional distances $f_{j} / z_{j}<f_{k} / z_{k}$.

9. In traditional inequality measurement the perfectly equal distribution is used as reference income, implying that perfect equality obtains if everyone has the same income. In this particular case, this class of distance measures reduces to the class of generalized entropy inequality measures $\left(z_{i}=\bar{z}=\bar{f}\right)$.

10. A description of the included variables and the results of the estimation of the probit model is given in the Appendix. To evaluate the statistical performance, a goodness-of-fit test was performed. McFadden's $R^{2}$ amounts to 0.1854 , indicating that the fit is reasonable. Complete estimation results are available upon request.

11. Such semi-logarithmic specification with the natural logarithm of income as left-hand-side variable is in line with the assumption that one has normality in the real world (see Maddala 1983, p. 33) and therefore leads to better estimation results (see Cramer 1991, p. 31). This has been a standard specification in the human capital literature since Mincer (1974).

12. Note that the determination coefficient $R^{2}$ is 0.47 , implying that it is impossible to assign $53 \%$ of the inequality to either component. The Breusch-Pagan test statistic indicates that the null hypothesis of homoscedasticity cannot be rejected.

13. This problem might be tackled in a technical, i.e. statistical, way as well. The problem then could be considered as decomposing a standard linear regression model $y=X \beta+u$ into two constituting parts, $y_{1}=X_{1} \beta_{1}+u_{1}$ and $y_{2}=X_{2} \beta_{2}+u_{2}$, where $u$ is known and $y=y_{1}+y_{2}$. We also know that $u=u_{1}+u_{2}$ but are ignorant about the specific value of $u_{1}$ and $u_{2}$. Attempts have been made to decompose $u$ into $u_{1}$ and $u_{2}$ statistically; see Schokkaert et al. (1998) and Dhaene et al. (2003).

14. Note, however, that this particular choice has a significant impact on the results. Calculations have shown that treating the residual as a responsability variable instead of as a compensation variable reduces the distance between the actual distribution and the norm distribution by about $50 \%$, ceteris paribus.

15. Others might find it more appealing that the income of the average productive member of the economy is considered as the income part that is independent of one's compensation variables. All results in Table 3 would in that case be revised downwards (except for GE, of course).

16. In exceptional cases, the egalitarian equivalent redistribution may imply that some people should have negative post-tax incomes. This might pose problems for the measures of distributional change, since these measures require that all incomes are positive. Checks on the data, however, revealed that no negative post-tax incomes were implied.

17. A related point has been made by Cappelen and Tungodden (2006).

\section{ACKNOWLEDGMENTS}

I would like to thank Erik Schokkaert and Frank Cowell for various suggestions that have led to improvements in this paper. I am very grateful for helpful comments from two anonymous referees and many seminar participants. I acknowledge financial support from the Training and Mobility of Researchers Program of the European Communities, grant no. ERBFMRXCT980248 (Living Standards, Inequality and Taxation).

\section{REFERENCES}

Arneson, R. J. (1989). Equality and equal opportunity for welfare. Philosophical Studies, 56, 77-93.

Babeuf, F. and Marechal, S. (1794). Manifeste des Egaux. Paris.

Bossert, W. (1995). Redistribution mechanisms based on individual characteristics. Mathematical Social Sciences, 29, 1-17.

— and Fleurbaey, M. (1996). Redistribution and compensation. Social Choice and Welfare, 13, $343-55$.

CAppelen, A. and Tungodden, B. (2003). Reward and responsibility: how should we be affected when others change their effort? Politics, Philosophy and Economics, 2, 191-211.

(C) The London School of Economics and Political Science 2007 
and (2006). Relocating the responsibility cut: should more responsibility imply less redistribution? Politics, Philosphy and Economics, 5, 353-62.

CoHen, G. (1989). On the currency of egalitarian justice. Ethics, 99, 906-44.

(1990). Equality of what? On welfare, goods and capabilities. Recherches Economiques de Louvain, 56, $357-82$.

Cowell, F. (1980). Generalized entropy and the measurement of distributional change. European Economic Review, 13, 147-59.

- (1985). The measurement of distributional change: an axiomatic approach. Review of Economic Studies, 52, 135-51.

Cramer, J. (1991). The Logit Model. London: Edward Arnold.

Danzinger, S., Haveman, R. and Smolensky, E. (1977). Comment on Paglin [1975]. American Economic Review, 67, 505-12.

Dhaene, G., Schokkaert, E. and VAn de Voorde, C. (2003). Best affine unbiased response decomposition. Journal of Multivariate Analysis, 86, 242-53.

Dworkin, R. (1981a). What is equality? Part 1: Equality of welfare. Philosophy and Public Affairs, 10, 185-246. (1981b). What is equality? Part 2: Equality of resources. Philosophy and Public Affairs, 10, 283-345.

EBERT, U. (1984). Measures of distance between income distributions. Journal of Economic Theory, 32, $266-74$.

Fleurbaey, M. (1994). On fair compensation. Theory and Decision, 36, 277-307. (1995a). The requisites of equal opportunity. In W. A. Barnett (ed.), Social Choice, Welfare, Ethics.

Cambridge: Cambridge University Press, pp. 37-53.

- (1995b). Three solutions for the compensation problem. Journal of Economic Theory, 65, 505-21.

(1995c). Equality and responsibility. European Economic Review, 39, 683-89.

(1995d). Equal opportunity or equal social outcome? Economics and Philosophy, 11, 25-55.

(1998). Equality among responsible individuals. In N. Gravel, M. Fleurbaey, J. F. Laslier and A.

Trannoy (eds.), Freedom in Economics. London: Routledge, pp. 206-34.

Formby, J. and SEAKs, T. (1980). Paglin's Gini measurement of inequality: a modification. American Economic Review, 70, 479-82.

— - and SMith, W. (1989). On the measurement and trend of inequality: a reconsideration. American Economic Review, 79, 256-64.

Heckman, J. (1979). Sample selection bias as a specification error. Econometrica, 47, 153-61.

JENKINS, S. P. (1994). Social welfare function measures of horizontal inequity. In W. Eichhorn (ed.), Models and Measurement of Welfare and Inequality. Berlin: Springer Verlag, pp. 725-51.

— and O'Higgins, M. (1989). Inequality measurement using 'norm incomes': were garvy and paglin onto something after all? Review of Income and Wealth, 35, 265-82.

Johnson, W. R. (1977). Comment on Paglin [1975]. American Economic Review, 67, 502-04.

Kurien, C. J. (1977). Comment on Paglin [1975]. American Economic Review, 67, 517-19.

Maddala, G. S. (1983). Limited-Dependent and Qualitative Variables in Econometrics, Econometric Society Monographs 3. Cambridge: Cambridge University Press.

MinariK, J. (1977). Comment on Paglin [1975]. American Economic Review, 67, 513-16.

MinCER, J. (1974). Schooling, Experience and Earnings. New York: Columbia University Press.

Nelson, E. R. (1977). Comment on Paglin [1975]. American Economic Review, 67, 497-501.

Paglin, M. (1975). The measurement and trend of inequality: a basic revision. American Economic Review, 65, $598-609$.

(1977). Reply. American Economic Review, 67, 520-31.

(1979). Reply to Wertz [1979]. American Economic Review, 69, 673-77.

(1989). On the measurement and trend of inequality: reply. American Economic Review, 79, $265-66$.

Peragine, V. (2004). Measuring and implementing equality of opportunity for income. Social Choice and Welfare, 22, 1-24.

Rawls, J. (1971). A Theory of Justice. Oxford: Oxford University Press.

Schokkaert, E., Dhaene, G. and van de Voorde, C. (1998). Risk adjustment and the trade-off between efficiency and risk selection: an application of the theory of fair compensation. Health Economics, 7, 465-80.

Shorrocks, A. F. (1982). On the distance between income distributions. Econometrica, 50, 1337-39.

Silber, J. (1995). Horizontal inequity, the gini index and the measurement of distributional change. Research on Economic Inequality, 6, 379-92.

Tungodden, B. (2005). Responsibility and redistribution: the case of first best taxation. Social Choice and Welfare, 24, 33-44.

Wertz, K. L. (1979). Comment on Paglin [1975]. American Economic Review, 69, 670-72. 


\section{Author Query Form}

\section{Journal ECCA}

Article $\quad 602$

Dear Author,

During the copy-editing of your paper, the following queries arose. Please respond to these by marking up your proofs with the necessary changes/additions. Please write your answers clearly on the query sheet if there is insufficient space on the page proofs. If returning the proof by fax do not write too close to the paper's edge. Please remember that illegible mark-ups may delay publication.

\begin{tabular}{|c|l|l|}
\hline Query No. & \multicolumn{1}{|c|}{ Description } & Author Response \\
\hline & No Queries & \\
\hline & & \\
\hline & & \\
\hline & & \\
\hline & & \\
\hline & & \\
\hline
\end{tabular}

